Saudi Journal of Medicine

Abbreviated Key Title: Saudi J Med ISSN 2518-3389 (Print) |ISSN 2518-3397 (Online) Scholars Middle East Publishers, Dubai, United Arab Emirates Journal homepage: https://saudijournals.com/sjm

Original Research Article

\title{
Imaging Characteristics of Primary Pancreatic Sarcoma: Review of Literature
}

\author{
Noha Abdullah Bakhsh* \\ King Abdulaziz University, Jeddah, Saudi Arabia
}

DOI: $10.36348 /$ sjm.2020.v05i01.011

| Received: 04.01.2020 | Accepted: 21.01.2020 | Published: 30.01 .2020

*Corresponding author: Noha Abdullah Bakhsh

Abstract

Introduction: Sarcoma is a rare entity with the primary pancreatic sarcoma represents a diagnostic challenge. Material and Methods: I reviewed articles particularly radiology studies in English language found in PubMed that were published recently to draw conclusions. Results: The common presenting symptom is vague abdominal pain. The described imaging appearance of such entity which shared between the different subtypes is a large heterogenous solid mass with frequent cystic degeneration/necrosis. The regional lymph nodes are rarely involved. Overall, poor prognosis of primary pancreatic sarcoma was reported. Conclusions: Although primary pancreatic sarcoma diagnosis remains a challenge, imaging differentiation from pancreatic ductal adenocarcinoma may be possible.

Keywords: sarcoma, nonepithelial, pancreas, neoplasm, CT, imaging.

Copyright @ 2020: This is an open-access article distributed under the terms of the Creative Commons Attribution license which permits unrestricted use, distribution, and reproduction in any medium for non-commercial use (NonCommercial, or CC-BY-NC) provided the original author and source are credited.

\section{INTRODUCTION}

Nonepithelial pancreatic neoplasms comprise only $1 \%-2 \%$. The mesenchymal tumors are being the most common type, with the leiomyosarcomas are most commonly reported subtype. Primary pancreatic sarcomas are rare and difficult to differentiate from retroperitoneal sarcoma with extension to pancreas [1].

\section{MATERIAL AND METHODS}

I searched PubMed for primary pancreatic sarcomas. The articles including radiologic studies which conducted recently were reviewed. Metastasis to pancreas and non-English reports were excluded.

\section{RESULTS}

The common presenting symptoms of primary pancreatic sarcomas are vague abdominal pain, palpable mass or as acute pancreatitis [1,2]. CT is the modality of choice for localization, lesion characterization and assessing local invasion for staging as well as evaluating for distal metastasis. The shared radiological findings between the different sarcoma subtypes is a large heterogenous solid mass with frequent cystic degeneration/necrosis and hemorrhage [3]. There are specific radiological features for some of the subtypes such as a variable fat component with solid nodules or septations in a liposarcoma and chondroid matrix in a chondrosarcoma [3]. Despite the relatively large size of such tumor at the time of presentation, patients are rarely present with jaundice as the bile and pancreatic ducts are not commonly affected [4-8]. Regional lymph nodes are rarely involved except in cases of a chondrosarcoma were nodal dissection is needed. Distant metastasis is well known in leiomyosarcomas subtype. Although poor prognosis of primary pancreatic sarcomas patients was reported, but still better than the observed with those who has pancreatic ductal adenocarcinoma [10-15].

\section{CONCLUSIONS}

A primary pancreatic sarcoma represents a challenge due to clinical and imaging features which may overlap with pancreatic ductal adenocarcinoma [9]. However, whenever a large well-defined pancreatic mass is found particularly with lack of biliary and pancreatic ductal dilatation a consideration of these rare tumors is suggested [3]. Also, a clinical absence of jaundice may support such a diagnosis. Awareness of these rare entity is important to direct appropriate clinical and/or surgical management.

\section{REFERENCES}

1. Hur, Y. H., Kim, H. H., Park, E. K., Seoung, J. S., Kim, J. W., Jeong, Y. Y., ... \& Cho, C. K. (2011). Primary leiomyosarcoma of the pancreas. Journal of the Korean Surgical Society, 81(Suppl 1), S69S73.

2. Csiszkó, A., László, I., Palatka, K., Szabó, K. G., Kanyári, Z., Bidiga, L., ... \& Szentkereszty, Z. 
(2015). Primary angiosarcoma of the pancreas mimicking severe acute pancreatitis-case report. Pancreatology, 15(1), 84-87.

3. Manning, M. A., Paal, E. E., Srivastava, A., \& Mortele, K. J. (2018). Nonepithelial neoplasms of the pancreas, part 2: malignant tumors and tumors of uncertain malignant potential from the radiologic pathology archives. Radiographics, 38(4), 1047-1072.

4. Xu, J., Zhang, T., Wang, T., You, L., \& Zhao, Y. (2013). Clinical characteristics and prognosis of primary leiomyosarcoma of the pancreas: a systematic review. World journal of surgical oncology, 11(1), 290.

5. Gabriel, M., \& Rubello, D. (2016). 18F-FDG PET-CT in soft tissue sarcomas: staging, restaging, and prognostic value?. Nuclear medicine communications, 37(1), 3-8.

6. Izumi, H., Okada, K. I., Imaizumi, T., Hirabayashi, K., Matsuyama, M., Dowaki, S., ... \& Makuuchi, H. (2011). Leiomyosarcoma of the pancreas: report of a case. Surgery today, 41(11), 1556-1561.

7. Qiu, L. L., Yu, R. S., Chen, Y., \& Zhang, Q. (2011, October). Sarcomas of abdominal organs: computed tomography and magnetic resonance imaging findings. In Seminars in Ultrasound, $C T$ and MRI, 32(5):405-421.

8. Cooley, C. L., Jagannathan, J. P., Kurra, V., Tirumani, S. H., Saboo, S. S., Ramaiya, N. H., \& Shinagare, A. B. (2014). Imaging Features and Metastatic Pattern of Non-IVC Retroperitoneal Leiomyosarcomas: Are They Different From IVC
Leiomyosarcomas?. Journal of computer assisted tomography, 38(5), 687-692.

9. Ambe, P., Kautz, C., Shadouh, S., Heggemann, S., \& Köhler, L. (2011). Primary sarcoma of the pancreas, a rare histopathological entity. A case report with review of literature. World journal of surgical oncology, 9(1), 85.

10. Jarry, J., Belleannee, G., Laurent, C., Coindre, J. M., \& Evrard, S. (2010). Primary malignant fibrous histiocytoma of the pancreas: benefit of the multidisciplinary approach. European journal of gastroenterology \& hepatology, 22(6), 765-768.

11. Bu, X., \& Dai, X. (2010). Primary mesenchymal chondrosarcoma of the pancreas. The Annals of The Royal College of Surgeons of England, 92(3), e10-e12.

12. Bose, P., Murugan, P., Gillies, E., \& Holter, J. L. (2012). Extraosseous Ewing's sarcoma of the pancreas. International journal of clinical oncology, 17(4), 399-406.

13. Xu, J., Zhang, T., Wang, T., You, L., \& Zhao, Y. (2013). Clinical characteristics and prognosis of primary leiomyosarcoma of the pancreas: a systematic review. World journal of surgical oncology, 11(1), 290.

14. Elliott, T. E., Albertazzi, V. J., \& Danto, L. A. (1980). Pancreatic liposarcoma. Case report with review of retroperitoneal liposarcomas. Cancer, 45(7), 1720-1723.

15. American Cancer Society. (2017). Cancer facts and figures 2017. Atlanta, Ga: American Cancer Society. 